\title{
ALLOMETRIC MODELS FOR ESTIMATING ABOVEGROUND BIOMASS AND CARBON STOGK IN PLANTED AQUILARIA MALACCENSIS STAND
}

\author{
Abd-Majid J, 2, *, Hazandy AH ${ }^{2,3}$, Nor-Azah MA $^{1} \&$ Johar $\mathbf{M}^{2,3}$ \\ ${ }^{1}$ Forest Research Institute Malaysia, 52109 Kepong, Selangor, Malaysia \\ ${ }^{2}$ Institute of Tropical Forestry and Forest Products, Universiti Putra Malaysia, 43400 UPM, Serdang, Selangor, Malaysia \\ ${ }^{3}$ Faculty of Forestry and Environment, Universiti Putra Malaysia, 43400 UPM, Serdang, Selangor, Malaysia \\ *majid@frim.gov.my
}

Submitted April 2020; accepted March 2021

\begin{abstract}
In Malaysia, the demand for high-value agarwood produced by Aquilaria spp. and efforts to reduce harvesting pressure on wild stands of these trees have resulted in an increase of Aquilaria plantations, which are harvested as a short-rotation (7 years) tree crop. Aquilaria spp. plantations potentially contribute to biomass accumulation as the trees are planted as reforestation and afforestation projects on marginal and idle lands but harvesting may affect their function as carbon sink. There are important environmental impact assessments of Aquilaria spp. plantations related to biomass and carbon sequestration. This study was conducted to develop an allometric model to estimate aboveground biomass and carbon stocks for plantation-grown Aquilaria spp. A census was conducted on 418 ten-year-old Aquilaria malaccencis trees on a 1-ha plot and measurements of height and stem diameter were used to categorise the trees into three diameter classes (small, medium, large). Ten trees were randomly selected for destructive sampling and developing allometric equations for estimating aboveground biomass. The recommended model, which used stem diameter as the predictor variable, estimated $23,615 \mathrm{~kg}$ total aboveground biomass for this 1-ha plot. Carbon analysis of stem, branches and foliage revealed an average carbon content of $40.35 \%$. Average carbon density was $285 \mathrm{~kg}$ tree $^{-1}$ and $9353 \mathrm{~kg} \mathrm{ha}^{-1}$. The 10 destructively sampled trees stored $1046 \mathrm{~kg} \mathrm{CO}{ }_{2}$ equivalent. Our findings provided baseline information on the biomass and carbon stock measurements for plantation-grown A. malaccensis and supported plantation in accumulating biomass and carbon storage.
\end{abstract}

Keywords: Agarwood, allometric equation, carbon sequestration, destructive sampling

\section{INTRODUCTION}

Aquilaria spp. (Thymelaeaceae) are known for their production of agarwood, a resin highly sought after for its fragrance and medicinal values and widely used in perfumes, incense and for religious purposes especially in the MiddleEast and Asian countries. The unsustainable harvesting of agarwood from wild stands of Aquilaria spp. in Malaysia is unable to meet the huge global demand for high grade agarwood, and is threatening the natural populations (Chua 2008, Nor Azah et al. 2013). Encouraged by the Malaysian government, planting of Aquilaria trees in Peninsular Malaysia by smallholders and private companies has increased the area under cultivation to 1119 ha (Ismail 2014). These plantations help conserve Aquilaria spp. in natural forests in Malaysia and provide a sustainable source of agarwood. Aquilaria malaccensis is the main species planted, largely as monoculture plantations or intercropped with rubber, palm oil or short-term cash crops (FDPM 2012). As the species grows well on marginal land under a wide range of soil conditions, A. malaccensis has been planted in reforestation and afforestation projects (Lok \& Zuhaidi 2016).

As a short rotation (7 years) forest tree crop, Aquilaria spp. plantations may help rehabilitate degraded lands, reduce harvesting pressure on wild Aquilaria populations and capture atmospheric carbon. The carbon sequestration of natural forests has been extensively reported, as with biomass and carbon stock dynamics in plantation forest. Information on biomass distribution and carbon stocks of $A$. malaccensis in plantations is limited although it would be of benefit in planting and management decisions. Forest biomass may be estimated by destructive 
harvesting, the (non-destructive) mean-tree method applicable to same-sized trees such as in plantations, or the allometric method, which applies allometric equations to estimate the whole or partial weight of a tree from measurable predictor variables (Komiyama et al. 2008). The predictors used can include tree stem diameter at $1.3 \mathrm{~m}$ height (D), wood specific gravity, total tree height, and forest type (dry, moist or wet) (Chave et al. 2005).

Our study was conducted to develop allometric equations for estimating aboveground biomass (AGB) and to assess carbon stock for plantation-grown A. malaccensis. The primary variable included in calculating biomass was $\mathrm{D}$. Relationships between other parameters such as tree height $(\mathrm{H})$, diameter class and aboveground tree components were also examined.

\section{MATERIALS AND METHODS}

\section{Study area and plot inventory}

The study was carried out at an A. malaccensis plantation $\left(3^{\circ} 37^{\prime} \mathrm{N}, 102^{\circ} 49^{\prime} \mathrm{E}, 100 \mathrm{~m}\right.$ above sea level) at the Maran FRIM Research Station, Pahang, located about $180 \mathrm{~km}$ east of Kuala Lumpur, Malaysia. An area of 2.5 ha was planted with $A$. malaccensis in 2008 at a planting density of 625 trees ha ${ }^{-1}(4 \mathrm{~m} \times 4 \mathrm{~m}$ spacing). The trees were fertilised at planting and every year for three years, circle-weeded for the first two years after planting, but not pruned because the desired agarwood forms in all above- and belowground parts of the tree. Dead trees were also not replaced. The topography of the study area is flat to undulating. Monthly report by the FRIM Maran Weather Station showed that mean annual rainfall, temperature and humidity for 2018 were $155.4 \mathrm{~mm}, 33{ }^{\circ} \mathrm{C}$ and $78 \%$ respectively.

A 1-ha plot of 10-year-old trees was established within the plantation and a census of the 418 surviving trees within was conducted. D and $\mathrm{H}$ were recorded for all trees and the values ranged from from $4.6-33.5 \mathrm{~cm}$ and $1.5-16.0 \mathrm{~m}$ respectively. All values were normally distributed. Small $(<15 \mathrm{~cm})$, medium $(15-25 \mathrm{~cm})$ and large $(>25 \mathrm{~cm})$ trees had mean $\mathrm{D}$ values of $11.3 \pm$ $0.2,19.4 \pm 02$ and $28.2 \pm 0.3 \mathrm{~cm}$ respectively and heights of $6.0 \pm 0.1,8.6 \pm 0.1$ and $10.3 \pm 0.3 \mathrm{~m}$ respectively ( $\mathrm{n}=122,248$ and 48 respectively).

\section{Destructive sampling}

To estimate AGB, we did a destructive sampling of 10 trees, which were randomly chosen using normal distribution statistics method to represent the three diameter classes, i.e. small, medium, and large. Discs measuring $2-3 \mathrm{~cm}$ thick were taken at 0.3 and $1.3 \mathrm{~m}$ aboveground level and then at every $2 \mathrm{~m}$ up the stem for all 10 trees (Hazandy et al. 2014). The fresh disc samples, the entire stem, foliage and branches (including twigs) were weighed and recorded as separate components in the field. Component samples were oven dried at $75^{\circ} \mathrm{C}$ to constant weight and their dry weights recorded.

\section{Biomass estimation}

Dry weight/fresh weight ratios for each component were used to estimate the total dry weight, i.e. biomass of that component for each tree (Heryati et al. 2011):

Biomass (M) of component $\mathrm{i}$,

$$
\mathrm{M}_{\mathrm{i}}=(\mathrm{SDW} / \mathrm{SFW}) \times \mathrm{TFW}
$$

where $\mathrm{i}=$ stem, foliage or branches, SDW $=$ sample dry weight, SFW = sample fresh weight, and TFW = total fresh weight.

Total AGB for each tree was obtained by adding the biomass of all three components for that tree:

$$
\text { Individual tree } \mathrm{AGB}=\sum \mathrm{M}_{\mathrm{i}}
$$

Nonlinear regression was used to develop two allometric models to predict individual plant foliage, branch and stem biomass, and total AGB from $\mathrm{D}$ and $\mathrm{H}$ using untransformed data and $\mathrm{a}$ power function of the forms:

$$
\begin{aligned}
& M_{i}=a(D)^{b} \\
& M_{i}=a\left(D^{2} H\right)^{b}
\end{aligned}
$$

where, $\mathrm{M}_{\mathrm{i}}=$ biomass of component $\mathrm{i}$ (i being stem, foliage or branches), or total AGB, $a, b=$ constants, $\mathrm{D}=$ tree diameter at $1.3 \mathrm{~m}$ height, and $\mathrm{H}=$ tree height

Goodness of fit for the regression equations was assessed by looking at p-values, standard error, 
the coefficient of determination, the coefficient of variation, and the residuals (observed minus predicted values) plotted against $\mathrm{D}$ and $\mathrm{H}$. The best-fit models were chosen as having the highest coefficient of determination, low p-value, standard error and coefficient of variation, and least bias. The internal consistency of the developed allometric relationship was checked by comparing observed (destructively harvested) and estimated values then the validated models were applied to estimating component and total AGB for the whole the stand of 418 trees.

\section{Estimation of carbon stock}

To estimate the aboveground carbon (AGC) content for each of the 10 destructively harvested trees, one composite foliage sample (50 g young, fully developed leaves), one composite branch/ twig sample (100 g other than leaves and stem) and six disc samples (two discs each from lower, middle and upper stem) were collected from each tree. A carbon analyser was used to directly determine the carbon content of the 80 dried component samples which were then divided by dry weight to give percent carbon content. Total AGC for each tree was obtained by adding the carbon content for all three components:

$$
\text { Individual tree } \mathrm{AGC}=\sum \mathrm{M}_{\mathrm{i}} \mathrm{C}_{\mathrm{i}}
$$

where, $\mathrm{M}_{\mathrm{i}}=$ total biomass for component $\mathrm{i}$, and $\mathrm{C}_{\mathrm{i}}=$ percent carbon content for component $\mathrm{i}$.

Individual tree AGG was converted to stand carbon stock $(\mathrm{kg})$ which was then multiplied by 3.6663 (whole tree carbon weight, or $\mathrm{CO}_{2}: \mathrm{C}$ ratio) to give $\mathrm{CO}_{2}$ equivalent for the 1-ha plot:

A two-way ANOVA was carried out to evaluate the effects of diameter class and tree components on AGB, carbon (\%) and carbon stock $(\mathrm{kg})$, with diameter class, tree components and their interaction as fixed factors. Duncan's multiple range test for post-hoc analyses was used to confirm differences between multiple group means.

\section{RESULTS AND DISCUSSION}

\section{Biomass estimation}

The two allometric models estimating the tree components and total AGB based on the independent variables $\mathrm{D}$ and $\mathrm{D}^{2} \mathrm{H}$ were comparable in their predictive values, both yielding $\mathrm{R}^{2}$ values greater than $90 \%$ and with standard error values lower than 2.5\% (Figure 1), indicating sufficiently precise models. Observed biomass values from the 10 destructively harvested trees were compared with AGB estimates from allometric equations in Figure 2. Generally, AGB derived from allometric equations underestimated the observed AGB but had $\mathrm{R}^{2}$ values greater than $97 \%$.

Total biomass of stems, branches and foliage were 312, 264 and $131 \mathrm{~kg}$ respectively, giving a total AGB of $707 \mathrm{~kg}$ (Table 1). The two models predicted higher branch biomass values and lower foliage biomass values than observed values but the model using D estimated total AGB closer to the observed value. Even though both models showed little difference in the estimated total AGB, the model using $\mathrm{D}$ estimated better than the equation using $\mathrm{D}^{2} \mathrm{H}$, with values of 23,615 and 22,905 $\mathrm{kg} \mathrm{ha}^{-1}$ respectively (Table 1). Adding $\mathrm{H}$ as a second variable to an equation containing $\mathrm{D}$ may decrease the average deviation of biomass estimates (Nelson et al. 1999) but our results showed no significant improvement in predictive ability when $\mathrm{H}$ was added to the model. Thus, since there was less work involved, we recommend using the model with $\mathrm{D}$ as the sole variable. In this study, the two models were not significantly different likely because, as in other same-age, single-species stands, $\mathrm{H}$ was proportional to D. Our study concurs with previous studies reporting $\mathrm{D}$ as the best predictor variable for estimating AGB (Banaticla et al. 2007, Chave et al. 2014, Khan et al. 2020) although $\mathrm{D}^{2} \mathrm{H}$ was the best predictor for $\mathrm{AGB}$ of three tree species in central Africa (Ebuy et al. 2011). Indeed, the D model has the advantage of needing only $\mathrm{D}$ measurements and not $\mathrm{H}$, which is time-consuming and hard to measure accurately especially where tree density is high (Heryati et al. 2011).

Our model may be used to estimate AGB of $A$. malaccensis stands of the same age and established under similiar conditions, but will need to be tested across a range of tree ages and planting sites to assess or refine its applicability as a generalised model. Most AGB equations that are developed for specific sites are not applicable to other locations (Van et al. 2000) but generalised equations have been proven to work. Examples include a single allometric equation estimating root and stem volumes of Acacia mangium under 


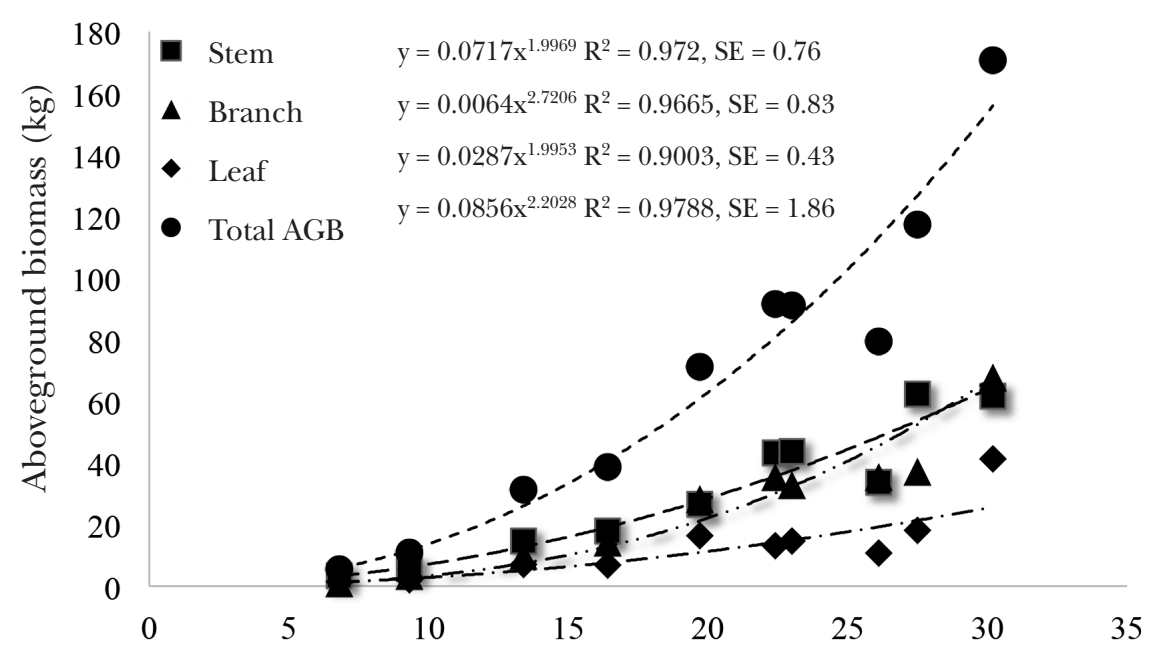

a) $\mathrm{D}(\mathrm{cm})$

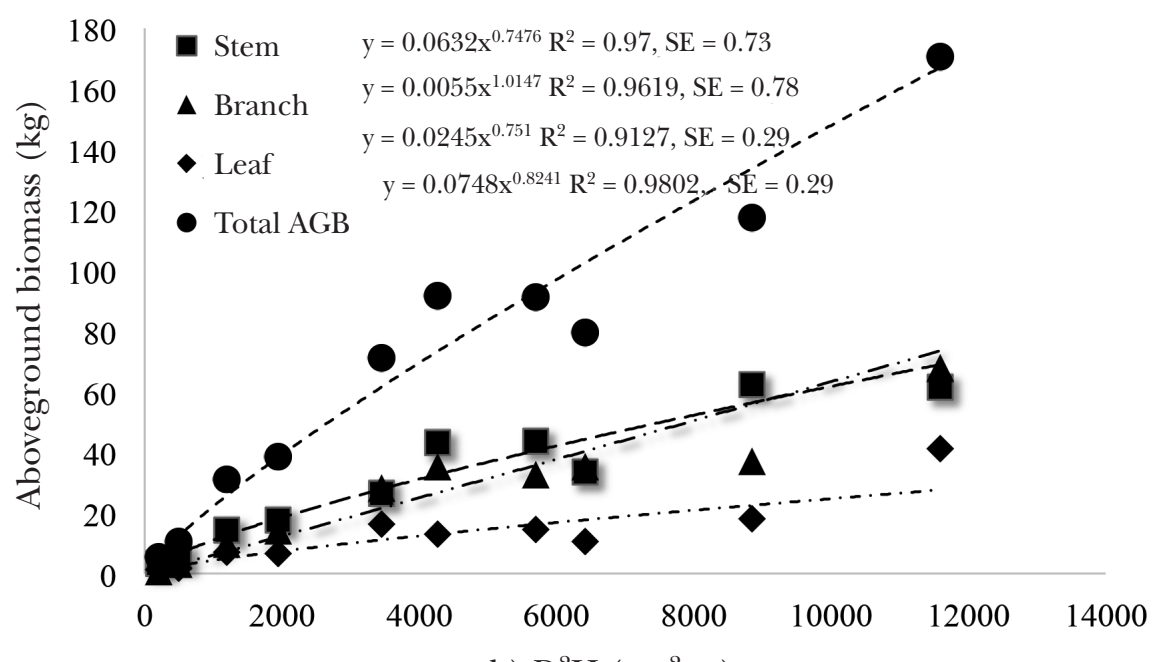

Figure 1 Allometric models for predicting foliage, branch, stem and total aboveground tree biomass using (a) diameter at breast height (D) and (b) $\mathrm{D}^{2} \mathrm{H} ; \mathrm{H}=$ height

Table 1 Observed (destructively harvested trees, $\mathrm{n}=10$ ) and predicted values (derived from allometric equations) of component and total aboveground (AGB) biomass using mean $\mathrm{D}$ and height $(\mathrm{H})$

\begin{tabular}{lcccc}
\hline Method & Stem & Branch & Foliage & Total AGB \\
\hline Average observed trees $\left(\mathrm{kg} \mathrm{trees}^{-1}\right)$ & & & & \\
$\quad$ Direct measurement & 31.2 & 26.4 & 13.1 & 70.7 \\
$\quad$ Model using D & 30.9 & 27.5 & 12.3 & 70.7 \\
$\quad$ Model using D ${ }^{2} \mathrm{H}$ & 31.1 & 27.6 & 12.4 & 71.1 \\
Total 418 trees (kg ha' $)$ & & & & \\
$\quad$ Model using D & 10,614 & 8604 & 4397 & 23,615 \\
$\quad$ Model using D & & & \\
\end{tabular}




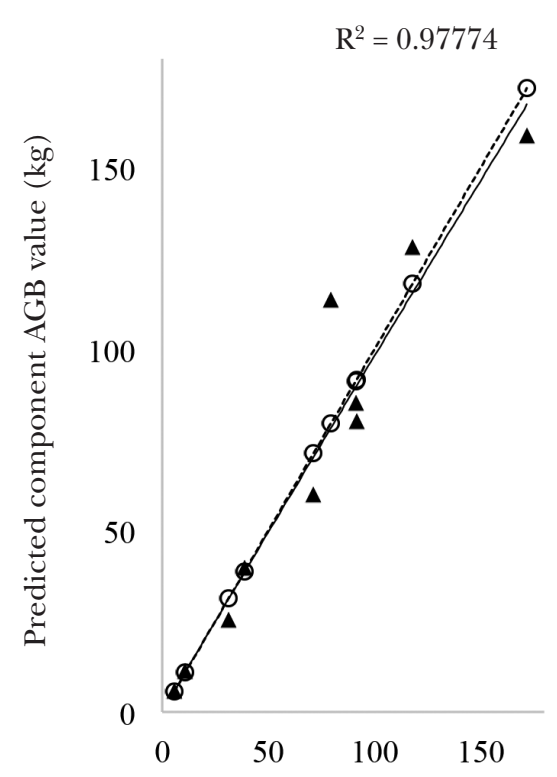

(a)

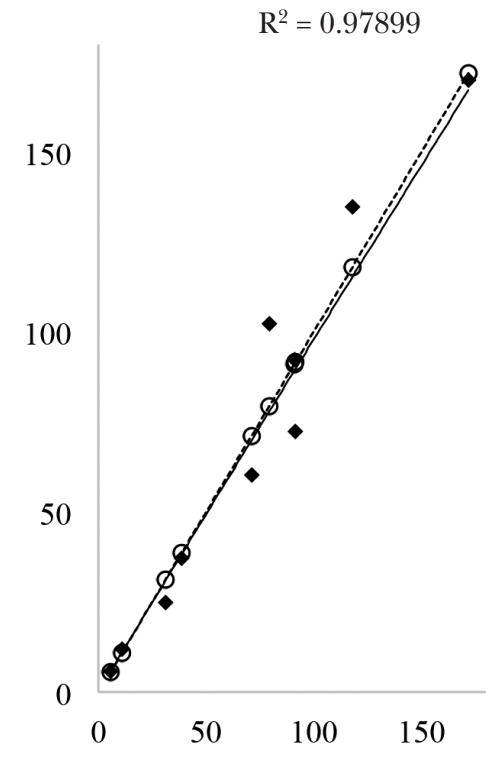

(b)

Observed component AGB value (kg)

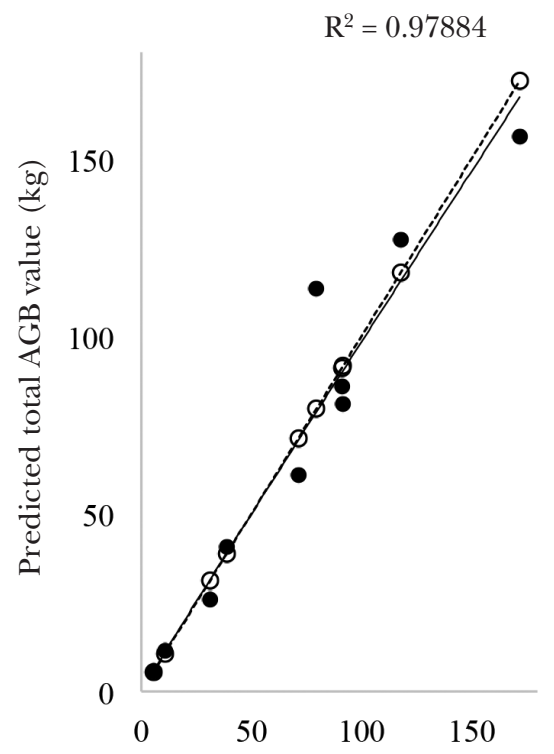

(c)

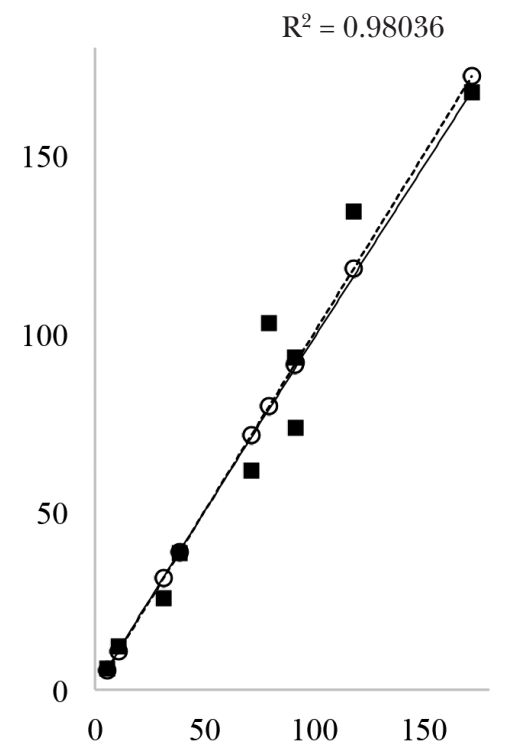

(d)

Observed total AGB value $(\mathrm{kg})$

Figure 2 Comparison of observed (destructively harvested trees) and predicted values (derived from allometric equations) for component AGB and total AGB using D (a, c respectively) and $\mathrm{D}^{2} \mathrm{H}$ (b, d respectively); predicted values are denoted by circles with dotted line while observed values are denoted by solid shapes with solid line

different management practices in Indonesia (Heriansyah et al. 2007), and a generalised allometric equation estimating AGB for Khaya ivorensis plantations on three soil series in Johor, Malaysia (Heryati et al. 2011).

Our study results showed biomass significantly increased with increasing diameter class (Table
2). Biomass differed significantly among tree components, with mean biomass of the stem $>$ branch $>$ foliage. There was no interaction between diameter class and tree component across biomass, percent carbon and carbon stock. While biomass may increase as trees (and D) grow larger (Forrester 2021), as seen in this 
study, a previous study reported no correlation between $\mathrm{D}$ and $\mathrm{H}$ with increasing age of 15 -yearold A. malaccensis and A. beccariana (Dwianto et al. 2019). The authors attributed their results to different growing conditions experienced by the trees.

\section{Estimation of carbon stock}

The AGC contents of the stems, branches/ twigs, and foliage were 119, 105 and $57 \mathrm{~kg}$ respectively (Table 3 ). Carbon percent was lowest in the stems $(38.04 \%)$ and highest in foliage $(43.42 \%)$, with an average of $40.35 \%$ across the three components. Carbon storage among forest types differ significantly (Birdsey 1992). The value obtained in this study was close to that reported for woody biomass $(47.00 \%)$ (IPCC 2006, Hengeveld et al. 2015) or proposed standard biomass-to-carbon conversion factor of 50\% (Schroeder 1993, Houghton et al. 1995).

Using the average AGC of $40.35 \%$ gave a total AGC content of $285 \mathrm{~kg}$ for the harvested trees which equalled to $9353 \mathrm{~kg}$ for the 1 -ha stand. The sampled trees stored $1046 \mathrm{~kg} \mathrm{CO}_{2}$ equivalent which gave an estimation of $34,291 \mathrm{~kg} \mathrm{CO}_{2}$ equivalent in the 1-ha stand. The carbon stock value in this study $\left(9353 \mathrm{~kg} \mathrm{ha}^{-1}\right)$ was far less than the $68,800 \mathrm{~kg} \mathrm{ha}^{-1}$ reported for $A$. malaccensis in a plantation in Bangladesh (Khan et al. 2020) but was much greater than the $810 \mathrm{~kg} \mathrm{ha}^{-1}$ reported for A. malaccensis in Siberut Island (Chairul et al. 2019). These differences in carbon stock may be attributed to the differences in biomass, tree size, age, composition and location, with foliar carbon concentration dependent on biomass, carbon absorption, soil fertility, plant diversity and density (IPCC 2006).

\section{CONCLUSIONS}

The findings of this study suggest the applicability of using a single allometric equation for estimating aboveground biomass and stand level carbon stocks over 10 years by plantation-grown A. malaccensis. Forest plantations can sequester atmospheric $\mathrm{CO}_{2}$ in biomass and play a role in reducing emissions and enhance forest carbon stocks. In this study, 10-year-old A. malaccensis stored $9353 \mathrm{~kg} \mathrm{ha}^{-1}$ of carbon. Further research is needed to determine if our developed model and estimated biomass and carbon stock values are applicable across a wider range of planting sites and tree ages.

\section{ACKNOWLEDGEMENTS}

This research was supported by the Fundamental Research Grant Scheme (Project No. FRGS/1/2020/ WAB03/KATS/03/1/FRGS(S).600-3/9/33311005003)

Table 2 Results of two-way ANOVA of the biomass, carbon percent and carbon content in the biomass of Aquilaria malaccensis trees

\begin{tabular}{lcccc}
\hline Source of variation & \multicolumn{3}{c}{ F-value and statistical significance } \\
\cline { 2 - 5 } & df & Biomass & Carbon $(\%)$ & Carbon $(\mathrm{kg})$ \\
\hline Diameter class (DC) & 2 & $30.777^{* *}$ & $2.101^{\mathrm{ns}}$ & $0.920^{\mathrm{ns}}$ \\
Tree component (TC) & 2 & $9.560^{* *}$ & $32.218^{* *}$ & $0.598^{\mathrm{ns}}$ \\
DC $\times$ TC & 4 & $2.426^{\mathrm{ns}}$ & $1.782^{\mathrm{ns}}$ & $0.540^{\mathrm{ns}}$ \\
\hline
\end{tabular}

$\mathrm{df}=$ degrees of freedom, $* \mathrm{p}<0.05, * * \mathrm{p}<0.01,{ }^{\mathrm{ns}}=$ not significant

Table 3 Observed (destructively harvested trees, $\mathrm{n}=10$ ) and estimated aboveground carbon of tree components

\begin{tabular}{|c|c|c|c|}
\hline \multirow[t]{2}{*}{ Tree component } & \multicolumn{2}{|c|}{ Observed } & \multirow{2}{*}{$\begin{array}{c}\text { Estimated } \\
\left(\mathrm{kg} \mathrm{ha}^{-1}\right)\end{array}$} \\
\hline & Actual $(\%)$ & $(\mathrm{kg})$ & \\
\hline Stem & 38.04 & 119 & 4038 \\
\hline Branch & 39.59 & 105 & 3406 \\
\hline Foliage & 43.42 & 57 & 1909 \\
\hline Total & & 285 & 9353 \\
\hline
\end{tabular}


and the Research, Pre-Commercialisation \& Publication Grants (Project No. $\operatorname{FRIM}(S) .600-1 / 11 / 9 / 41311005006)$ from Forest Research Institute Malaysia (FRIM). The authors would like to thank the research group of the Product Development Programme, FRIM for their invaluable support. Special thanks to staff of the Institute of Tropical Forestry and Forest Products, Universiti Putra Malaysia for field and laboratory assistance.

\section{REFERENCES}

Banaticla MRN, SAles RF \& Lasco RD. 2007. Biomass equations for tropical tree plantation species in young stands using secondary data from the Philippines. Annals of Tropical Research 29: 73-90.

BIRDSEY RA. 1992. Carbon Storage and Accumulation in United States Forest Ecosystems. General Technical Report WO-59. United States Department of Agriculture, Washington DC.

Chairul, Indra G, Muchtar E, Nurainas \& Mansyurdin. 2019. Study of carbon stock potential and carbon absorption on Pamonean land of Mentawai community at Siberut Island. KnE Engineering 4: 51-61. https://doi.org/10.18502/keg.vli2.4431

Chave J, Andalo C, Brown S et Al. 2005. Tree allometry and improved estimation of carbon stocks and balance in tropical forests. Oecologia 145: 87-99.

Chave J, Rejou-Mechain M, Búrquez A et al. 2014. Improved allometric models to estimate the aboveground biomass of tropical trees. Global Change Biology 20: 3177-3190. doi: 10.1111/gcb.12629

Chua LSL. 2008. NDF Workshop Working Group 1 Case Study 3: Agarwood (Aquilaria malaccensis) in Malaysia. International Expert Worshop on CITES NonDetriment Findings, Cancun.

Dwianto W, Kusumah SS, Darmawan T et al. 2019. Anatomical observation and characterization on basic properties of agarwood (gaharu) as an Appendix II CITES. IOP Conference Series: Earth and Environmental Science 374: 012062. https://doi. org/10.1088/1755-1315/374/1/012062

Ebuy J, Lokombe JP, Ponette Q, Sonwa D \& Picard N. 2011. Allometric equation for predicting aboveground biomass of three tree species. Journal of Tropical Forest Science 23: 125-132.

FDPM (Forestry Department of Peninsular Malaysia). 2012. Panduan Penanaman Karas. FDPM, Kuala Lumpur.

Forrester DI. 2021. Does individual-tree biomass growth increase continuously with tree size? Forest Ecology and Management 481: 118717.

Hazandy AH, Ahmad-Ainuddin N, Zaiton S et al. 2014. Quantifying aboveground carbon stock of 30-year- old mangrove forest and its economic value. Pp 188-213 in Poh LY et al. (eds) Prosiding Persidangan Kebangsaan Penilaian Ekonomi Sumber Hutan. 2-5 September 2014, Putrajaya.

Heriansyah I, Miyakuni K, Kato T, Kiyono Y \& Kanazawa Y. 2007. Growth characteristics and biomass accumulations of Acacia mangium under different management practices in Indonesia. Journal of Tropical Forest Science 19: 226-235.

Heryati Y, Debora B, Ariffin A et al. 2011. Growth performance and biomass accumulation of a Khaya ivorensis plantation in three soil series of ultisols. American Journal of Agricultural and Biological Science 6: 33-44.

Hengeveld GM, Gunia K, Didion M et Al. 2015. Global 1-Degree Maps of Forest Area, Carbon Stocks, and Biomass, 1950-2015. ORNL DAAC, Oak Ridge. http://dx.doi.org/10.3334/ORNLDAAC/1296

Houghton JT, Meira Filho LG, Bruce JP, Lee H, Callander BA \& Haites EF (eds). 1995. Climate Change 1994: Radiative Forcing of Climate Change and an Evaluation of the IPCC 1992 IS92 Emission Scenarios. Cambridge University Press, Cambridge.

ipCC (Intergovernmental Panel on Climate Change). 2006. 2006 IPCC Guidelines for National Greenhouse Gas Inventories. Institute for Global Environmental Strategies. Kamiyamaguchi.

IsMaIL M. 2014. Cabaran dan halatuju perladangan karas di Malaysia. https://www.academia.edu/7116198/ Perladangan_Karas_di_Malaysia.

Khan MNI, Islam MR, Rahman A et al. 2020. Allometric relationships of stand level carbon stocks to basal area, tree height and wood density of nine tree species in Bangladesh. Global Ecology and Conservation 22: e01025. doi: https://doi. org/10.1016/j.gecco.2020. e01025.

Komiyama A, Ong JE, Poungparn S. 2008. Allometry, biomass, and productivity of mangrove forests: a review. Aquatic Botany 89: 128-137.

Lok EH \& Zuhaidi AY. 2016. Growth and management of Aquilaria malaccensis for agarwood: a new domestication perspective. International Journal of Agriculture, Forestry and Plantation 3: 55-60.

Nelson BW, Mesquita R, Pereira JL et al. 1999. Allometric regressions for improved estimate of secondary forest biomass in the central Amazon. Forest Ecology and Management 117: 149-167.

Nor Azah MA, Saidatul Hs, Mailina J et al. 2013. Classification of agarwood (gaharu) by resin content. Journal of Tropical Forest Science 25: 213-219.

Schroeder P. 1993. Agroforestry systems: integrated land use to store and conserve carbon. Climate Research 3: 53-60.

VAn TK, Rayachhetry MB \& Center TD. 2000. Estimating aboveground biomass of Melaleuca quinquenervia in Florida, USA. Journal of Aquatic Plant Management 38: 62-67. 